\title{
Occurrences, sources and risk assessment of short- and medium-chain chlorinated paraffins in sediments from the middle reaches of the Yellow River, China
}

\author{
Lin Qiao ${ }^{\text {a, b }}$, Dan Xia ${ }^{\text {a, b }}$, Lirong Gao ${ }^{\text {a, b, * , Huiting Huang }}{ }^{\text {a, b }}$, Minghui Zheng ${ }^{\text {a, b }}$ \\ a State Key Laboratory of Environmental Chemistry and Ecotoxicology, Research Center for Eco-Environmental Sciences, Chinese Academy of Sciences, \\ Beijing 100085, China \\ ${ }^{\mathrm{b}}$ University of Chinese Academy of Sciences, Beijing 100049, China
}

\section{A R T I C L E I N F O}

\section{Article history:}

Received 24 March 2016

Received in revised form 19 May 2016

Accepted 20 May 2016

Available online 29 May 2016

\section{Keywords:}

Short-chain chlorinated paraffins

Medium-chain chlorinated paraffins

Sediments

The Yellow River

Homolog patterns

\begin{abstract}
A B S T R A C T
Chlorinated paraffins (CPs), one class of hydrophobic and toxic compounds, are easily adsorbed into sediments and then pose potential risks to the ecosystem and human health. However, few researches on short- and medium-chain CPs (SCCPs and MCCPs) in sediments have been performed. In order to comprehensively investigate the spatial distributions, sources, and ecological risks of CPs, sediments collected from the middle reaches of the Yellow River were analyzed by two-dimensional gas chromatography coupled with time-of-flight mass spectrometry (GC $\times$ GC-TOFMS). The concentrations of SCCPs and MCCPs ranged from 11.6 to $9.76 \times 10^{3} \mathrm{ng} / \mathrm{g}$ dry weight (dw) and from 8.33 to $168 \mathrm{ng} / \mathrm{g} \mathrm{dw}$, respectively. No significant correlation was found between total organic carbon (TOC) and CP concentrations $(P>0.05)$. The spatial distributions showed that contamination levels of CPs were relevant to human activities. In addition, two types of sediment samples were classified by hierarchical cluster analysis (HCA) and results indicated the predominant congener groups were $\mathrm{C}_{10} \mathrm{Cl}_{6-7}$ for SCCPs and $\mathrm{C}_{14} \mathrm{Cl}_{7-8}$ for MCCPs. Principal component analysis (PCA) revealed that SCCPs and MCCPs in the sediments may have different sources, and SCCPs are likely to come from the production and use of CP-42 and CP52. Moreover, complex environmental processes, including long-range transportation via the atmosphere and/or river, deposition and degradation of CPs, resulted in increased abundances of short chain and low chlorinated congeners in sediment samples compared with commercial mixtures, and different homolog patterns among samples. The significant negative correlation between SCCP concentrations and MCCP/SCCP ratios could be related to long-range transport of CPs. A preliminary risk assessment indicated that CPs at current levels posed no significant ecological risk.
\end{abstract}

๑) 2016 Elsevier Ltd. All rights reserved.

\section{Introduction}

Chlorinated paraffins (CPs) are a class of complex technical mixtures, containing thousands of isomers, enantiomers, diastereomers and congeners (Bayen et al., 2006; Feo et al., 2009). According to the carbon chain length, CPs can be grouped into short-chain CPs (SCCPs, $\mathrm{C}_{10-13}$ ), medium-chain CPs (MCCPs, $\mathrm{C}_{14-17}$ ) and long-chain CPs (LCCPs, $\mathrm{C}_{18-30}$ ). Owing to the potential for longrange transport (Tomy et al., 1999), persistence (Iozza et al., 2008), bioaccumulation (Fisk et al., 2000) and toxicity (Warnasuriya et al.,

\footnotetext{
* Corresponding author. State Key Laboratory of Environmental Chemistry and Ecotoxicology, Research Center for Eco-Environmental Sciences, Chinese Academy of Sciences, Beijing 100085, China.

E-mail address: gaolr@rcees.ac.cn (L. Gao).
}

2010), SCCPs have been listed as persistent organic pollutants (POPs) candidate in the Stockholm Convention. The chemical and thermal stabilities of CPs have led them to be widely produced and used as plasticizers, lubricant additives, coolants and/or flame retardants, and in applications such as metal working fluids and sealants (Feo et al., 2009). CPs can be released into the environment during production, storage, transportation, use and disposal of these related manufactured products. Besides, CPs may also enter the environment through waste incineration (Feo et al., 2009), sewage treatment (Zeng et al., 2012b) and e-waste dismantling (Lu et al., 2015). Up to now, CPs have been found to be widespread in the air (Wang et al., 2013), water (Coelhan, 2010), soil (Wang et al., 2014), sediment (Zeng et al., 2013), aquatic and terrestrial wildlife (Reth et al., 2006; Zeng et al., 2015), and even in human breast milk (Thomas et al., 2006). So it's important to improve our understanding of the pollution status and potential risks posed by CPs. 
China is the largest producer and consumer of CPs in the world. The annual production has been continuously and rapidly increasing, up to $6 \times 10^{5}$ tons in 2007 (De Boer et al., 2010) and $1 \times 10^{6}$ tons in 2009 (Chen et al., 2011), so that CPs are released into the environment on a large scale (Ma et al., 2014a; Wang et al., 2012, 2014; Zeng et al., 2011a; Zeng et al., 2012b). Because of their high Koc values (Fisk et al., 1998), CPs are easily adsorbed into sediments. They can be accumulated by the sediment-dwelling organisms and then pose potential risks to humans after being further accumulated through the food chain (Houde et al., 2008; Ma et al., 2014b). So the sediment can be regarded as an important sink of CPs. On the other hand, CPs in sediments can be rereleased to the water and affect aquatic organisms, causing secondary pollution. It's therefore necessary to investigate $\mathrm{CP}$ contamination levels in sediments so as to reveal the sources and then put forward corresponding control measures.

Several previous studies have reported the concentrations and distributions of CPs in sediments from some regions. River Sediments from the Liaohe River Basin (China) and the Czech Republic were investigated, suggesting that local industrial activities were major sources of SCCPs (Gao et al., 2012; Pribylova et al., 2006). Researches about marine sediments from the East China Sea, Bohai and Yellow Seas indicated that CP concentrations increased with time, but decreased with the distance away from the coast (Zeng et al., 2012a, 2013). A study of sediment samples collected near a sewage treatment plant (STP) demonstrated that STP effluents could be important sources of SCCPs (Zeng et al., 2011b). However, there is no systematical discussion about the factors influencing $\mathrm{CP}$ homolog patterns, which are closely associated with the toxicity of CPs (De et al., 2010; Wyatt et al., 1993). Although the production and use of SCCPs has been restricted in some regions, MCCPs were produced as the replacement chemicals in a high level (EU, 2011). Data on MCCPs is scarcer than SCCPs due to the difficulties with analytical methods. Although toxicity of MCCPs is lower compared to SCCPs (Wyatt et al., 1993), MCCPs have also shown bioaccumulation (Houde et al., 2008) and even higher concentration levels (Chen et al., 2011) in some studies, suggesting that more attention should be paid to MCCPs than is currently the case. The Yellow River, regarded as the second longest river in China, is the main water supply for North China. With rapid industrialization and urbanization along the river, especially in the middle reaches of the river, an increasing number of electronic factories, metallurgical factories and petrochemical plants were set up. Moreover, a large volume of CP manufacturers have been established nearby, which could be potential emission sources of CPs.

In this study, two-dimensional gas chromatography coupled with time-of-flight mass spectrometry (GC $\times$ GC-TOFMS) was used to analyze SCCPs and MCCPs in sediments from the middle reaches of the Yellow River. The objectives were to gain knowledge of the spatial distributions and congener group profiles of SCCPs and MCCPs in river sediments. The contamination sources, transport pathways and environmental fates of CPs were then explored and the factors influencing $\mathrm{CP}$ homolog patterns in sediments were revealed. Finally, ecological risks posed by SCCPs were assessed based on existing toxicology data. It is hoped that our work will be helpful to better understand current pollution status and environmental behaviors of CPs, as well as put forward some strategies for future reduction of CPS in the environment.

\section{Materials and methods}

\subsection{Sample collection}

Thirteen surface sediment samples $(0-5 \mathrm{~cm}$ deep) were collected from the middle reaches of the Yellow River (Fig. S1,
Supporting Information) using a grab sampler. At each sampling site, five separate samples were collected and then mixed together. After removing stones and roots, samples were freeze-dried, ground and then sieved via a 60 mesh sieve. Finally, all samples were sealed in amber glass bottles, labeled and stored at $-20{ }^{\circ} \mathrm{C}$ until analysis.

\subsection{Chemicals and materials}

Three commercial SCCP standards (with chlorine contents of $51.5 \%, 55.5 \%$, and $63 \%$ ) and three MCCP standards (with chlorine contents of $42 \%, 52 \%$, and $57 \%$ ) at $100 \mathrm{ng} / \mu \mathrm{L}$ in cyclohexane were obtained from Dr. Ehrenstorfer (Augsburg, Germany). SCCP solutions with $53.5 \%$ and $59.2 \%$ chlorine content were prepared by mixing equal volumes of SCCP standards with chlorine contents of $51.5 \%$ and $55.5 \%$, as well as $55.5 \%$ and $63 \%$, respectively. Similarly, MCCPs with $47 \%$ and $54.5 \%$ chlorine content were gained by mixing MCCPs of $42 \%$ and $52 \%$, as well as $52 \%$ and $57 \%$. These above CP solutions with different chlorine contents were used to establish linear calibration curves between total response factors and chlorine contents. ${ }^{13} \mathrm{C}_{10}$-trans-chlordane purchased from Cambridge Isotope Laboratories (Andover, USA), and $\varepsilon$-hexachlorocyclohexane $(\varepsilon-\mathrm{HCH})$ obtained from Dr. Ehrenstorfer were used as surrogate and internal standards, respectively. Silica gel (63-100 $\mu \mathrm{m})$ and Florisil (60-100 mesh) were purchased from Merck (Whitehouse Station, NJ). Anhydrous sodium sulfate was purchased from Sinopharm Chemical Reagent Co (Beijing, China). Before use, silica gel was activated at $550^{\circ} \mathrm{C}$ for $12 \mathrm{~h}$, anhydrous sodium sulfate was baked at $660^{\circ} \mathrm{C}$ for $6 \mathrm{~h}$, and Florisil was baked at $140{ }^{\circ} \mathrm{C}$ overnight. Acid silica gel $(30 \%, w / w)$ was prepared by mixing $100 \mathrm{~g}$ activated silica gel with $23.3 \mathrm{~mL}$ concentrated sulfuric acid.

\subsection{Sample extraction and cleanup}

In this study, the extraction and clean-up procedures were modified based on previous studies (Gao et al., 2011; Zeng et al., 2011a). Briefly, $5 \mathrm{~g}$ homogenized sediment was spiked with $2.5 \mathrm{ng}{ }^{13} \mathrm{C}_{10}$-trans-chlordane, and then extracted via an accelerated solvent extractor (ASE). Three static extraction cycles were performed, each using 30-40 $\mathrm{mL} n$-hexane/dichloromethane $(1: 1, \mathrm{v} / \mathrm{v})$ for $10 \mathrm{~min}$ at $1.03 \times 10^{4} \mathrm{kPa}$ and $150{ }^{\circ} \mathrm{C}$. Next, the extract was concentrated to approximately $1 \mathrm{~mL}$ and then passed through a gel permeation chromatography (GPC) column to remove sulfurcontaining compounds. The eluent was concentrated again and then fractionated on a $1.5 \mathrm{~cm}$ i.d. silica-Florisil composite column containing, from the bottom to top, $3 \mathrm{~g}$ Florisil, $2 \mathrm{~g}$ neutral silica gel, $5 \mathrm{~g} \mathrm{30 \%}$ acid silica gel and $4 \mathrm{~g}$ anhydrous sodium sulfate. The column was conditioned with $50 \mathrm{~mL} n$-hexane, and the sample was eluted with $40 \mathrm{~mL} n$-hexane, followed by $100 \mathrm{~mL} n$-hexane/ dichloromethane (1:1). The second fraction was concentrated to near dryness under a gentle stream of $\mathrm{N}_{2}$ and then reconstituted in $50 \mu \mathrm{L}$ cyclohexane. Prior to analysis, $2.5 \mathrm{ng} \varepsilon-\mathrm{HCH}$ was added.

\subsection{Instrumental analysis}

The GC $\times$ GC - TOFMS analysis was conducted using an Agilent 7890A GC instrument (Agilent Technologies, Santa Clara, USA) equipped with a ZX2004 loop cryogenic modulator (Zoex Corporation, Houston, USA) and a high resolution time-of-flight mass spectrometry instrument (Tofwerk, Thun, Switzerland), according to our previous study (Xia et al., 2016). The first-dimension column was a DB-5MS column $(30 \mathrm{~m} \times 0.25 \mathrm{~mm}$ i.d. $\times 0.25 \mu \mathrm{m}$ film thickness, Agilent Technologies, Santa Clara, USA), and the seconddimension column was a BPX-50 column $(1 \mathrm{~m} \times 0.1 \mathrm{~mm}$ i.d. $\times 0.1 \mu \mathrm{m}$ film thickness, SGE, Melbourne, Australia). The carrier 
gas was helium at a flow rate of $1.0 \mathrm{~mL} / \mathrm{min}$. Each $1 \mu \mathrm{L}$ sample was injected in splitless mode, and the injector temperature was $280^{\circ} \mathrm{C}$. The oven temperature started at $140{ }^{\circ} \mathrm{C}$ (held for $1 \mathrm{~min}$ ), increased to $200{ }^{\circ} \mathrm{C}$ at $10^{\circ} \mathrm{C} / \mathrm{min}$, then increased to $310^{\circ} \mathrm{C}$ at $1.5^{\circ} \mathrm{C} / \mathrm{min}$ (held for $5 \mathrm{~min}$ ). The modulation period was $8 \mathrm{~s}$. Besides, the mass spectrometer was operated in the electron capture negative ionization mode (ECNI) with electron collision energy of $125 \mathrm{eV}$. And the reagent gas was methane. The transfer line was kept at $280{ }^{\circ} \mathrm{C}$, and the ion source temperature was $200{ }^{\circ} \mathrm{C}$.

The GC $\times$ GC chromatogram contained 12 groups of ordered structures on diagonal lines, and each group consisted of CP congeners with the same total number of carbon atoms and chlorine atoms (e.g., $\mathrm{C}_{10} \mathrm{H}_{14} \mathrm{Cl}_{8}, \mathrm{C}_{11} \mathrm{H}_{17} \mathrm{Cl}_{7}$, and $\mathrm{C}_{12} \mathrm{H}_{20} \mathrm{Cl}_{6}, \mathrm{C}_{13} \mathrm{H}_{23} \mathrm{Cl}_{5}$ ). For each formula congener, the most abundant $[\mathrm{M}-\mathrm{Cl}]^{-} \mathrm{m} / \mathrm{z}$ was selected as the quantification ion, and the second most abundant as the qualification ion (Table S1). The characteristic ions of different CP formula congeners within each group were extracted respectively so as to effectively eliminate interferences from other substances. All 48 SCCP congener groups $\left(C_{10}-C_{13}\right.$ with $5-10$ chlorine atoms) and $\mathrm{MCCP}$ congener groups $\left(\mathrm{C}_{14}-\mathrm{C}_{17}\right.$ with $5-10$ chlorine atoms) were therefore able to be simultaneously monitored in one injection. The total concentrations of SCCPs and MCCPs in sediment samples were calculated based on a procedure previously described (Reth et al., 2005). Linear correlations between the total response factors of SCCP and MCCP standard mixtures as well as the corresponding chlorine contents were obtained. In this way, differences in the chlorine contents between practical samples and referenced $\mathrm{CP}$ mixtures could be corrected to give reliable quantification results. All GC $\times$ GC data were viewed and processed using GC Image ${ }^{\circledR}$ R2.5 Software (GC Image, Lincoln, USA).

\subsection{Total organic carbon analysis}

About $0.1 \mathrm{~g}$ of each sediment sample was treated with $5 \%$ phosphoric acid to remove residual carbonate. The TOC contents of those sediments were then measured using a TOC Analyzer (O.I. Analytical, College Station, TX, USA).

\subsection{Quality control and quality assurance}

Each batch of six sediment samples included a procedural blank to check possible cross contamination. Three sediment samples among thirteen sediment samples were randomly selected to perform the parallel analysis. The results of relative standard deviations (RSD) were less than $15 \%(n=7)$. The recovery was calculated via the ratio of the cleanup standard $\left({ }^{13} \mathrm{C}_{10}\right.$-trans-chlordane) and injection internal standard $(\varepsilon-\mathrm{HCH})$ in samples compared with standard solutions. The measured recoveries were $72.5-93.8 \%$ and the final results were not corrected by the surrogate recoveries. The method detection limits (MDLs) of SCCPs and MCCPs were defined as the average amount found in the blanks plus three times the standard deviation of repeated instrumental measurements. The MDLs were estimated to be $2.72 \mathrm{ng} / \mathrm{g}$ for $\sum \mathrm{SCCPs}$ and $1.98 \mathrm{ng} / \mathrm{g}$ for $\sum$ MCCPs, respectively.

\section{Results and discussion}

\subsection{Concentrations and spatial distributions of SCCPS and MCCPs in sediments}

Concentrations of SCCPs and MCCPs in sediments from the middle reaches of the Yellow River were all reported on a dry weight ( $\mathrm{dw}$ ) basis. As shown in Table 1, the SCCP concentrations in the sediment samples ranged from 11.6 to $9.76 \times 10^{3} \mathrm{ng} / \mathrm{g} \mathrm{dw}$, and the chlorine contents of SCCPs were calculated to be in the range of
$61.9-62.9 \%$.

The highest SCCP concentration was found in the sample from site Y13 $\left(9.76 \times 10^{3} \mathrm{ng} / \mathrm{g} \mathrm{dw}\right)$, and the concentrations in other samples ranged from 11.6 to $809 \mathrm{ng} / \mathrm{g}$ dw. Compared with previous studies about SCCPs in sediments, as shown in Fig. 1, the concentrations in our samples were generally equivalent to those found in Liaohe River Basin (39.8-480.3 ng/g dw) (Gao et al., 2012) and the Liaodong Bay (65-541 ng/g dw) (Ma et al., 2014b), but higher than those from the East China Sea (5.8-64.8 ng/g dw) (Zeng et al., 2012a) and the Firth of Clyde in Scotland (0.4-69 ng/g dw) (Hussy et al., 2012), and rivers in the Czech Republic (4-347 ng/g dw) (Zeng et al., 2013), as well as lower than those in typical industrial regions, such as the coastal area of Barcelona in Spain $(0.21-1.17 \mu \mathrm{g} / \mathrm{g}$ dw) (Castells et al., 2008) and the Pearl River Delta (320-6600 ng/g dw) (Chen et al., 2011).

As shown in Fig. 2, the SCCP concentrations in sediments from sites $\mathrm{Y} 1$ to $\mathrm{Y} 6$, in the upper reaches of investigated Yellow River Basin, were $11.6-53.4 \mathrm{ng} / \mathrm{g} \mathrm{dw}$. These concentrations were lower than the concentrations found in other samples, probably because of the absence of anthropogenic emissions of CPs nearby. However, SCCP concentrations significantly increased in the middle- and down-streams of the Yellow River Basin. This may be related to those industries, including electronic manufacturing, plastic manufacturing, and petrochemical plants, located in these areas. The use and disposal of CPs in these plants may be the main reason for increased CP levels in sediments. In particular, sample Y8, which was collected in the downstream of Zhengzhou and Kaifeng Sewage treatment plants (STP) mainly receiving industrial wastewater, had higher SCCP concentration at $808 \mathrm{ng} / \mathrm{g} \mathrm{dw}$. This implied that STP effluents may be sources of SCCPs at the site. It was consistent with previous studies (Zeng et al., 2011b). In addition, the contamination level of SCCPs in site Y13 was much higher than any others, suggesting that there may be some SCCP emission sources nearby.

The MCCP concentrations were in the range of $8.33-168 \mathrm{ng} / \mathrm{g}$ dw, much lower than those found from the Pearl River Delta (880-38,000 ng/g dw) (Chen et al., 2011) and the Czech Republic (18-5575 ng/g dw) (Pribylova et al., 2006), as shown in Fig. 1(b). The chlorine contents of MCCPs in all of the sediment samples were $57.1-59.9 \%$. The spatial distributions of MCCPs were similar to that of SCCPs except that the highest MCCP concentration was not found at site Y13. In other words, the MCCP concentrations in sampling sites tended to decrease with distance away from cities. The MCCP concentrations were lower than SCCPs in all of the samples, which probably be related to the difference in emission and transmission of CPs.

It is generally believed that the TOC content is a key factor influencing the adsorption of organic compounds in sediments. Significant relationships between TOC and CP concentrations have been found in some studies, indicating that the TOC content played an important role in the accumulation of CPs in sediments (Chen et al., 2011; Zeng et al., 2013). However, no significant relationships were found in other studies, which highlighted the influence of emission sources (Gao et al., 2012). In this study, TOC contents of the sediments ranged from $0.21 \%$ to $1.92 \%$ (Table S2). No significant correlation between TOC and SCCP concentrations was found via Spearman correlation analysis $(\mathrm{P}>0.05)$, and the same result was observed between TOC and MCCP concentrations (Table S3). Therefore, variations of SCCP and MCCP concentrations in sediments were not absolutely relied on the organic matter contents, suggesting that CPs may be introduced into the sediments continuously, and the equilibrium partition of CPs between sediments and other environmental compartments such as air and water has not been well established. 
Table 1

Concentrations of SCCPs and MCCPs and relative contents of CP homolog groups in sediments from the middle reaches of the Yellow River, China.

\begin{tabular}{|c|c|c|c|c|c|c|c|c|c|c|c|c|}
\hline \multirow[t]{2}{*}{ Sample no. } & \multirow[t]{2}{*}{$\mathrm{Cl} \%-\mathrm{SCCPs}$} & \multicolumn{5}{|c|}{ Relative content or concentration (ng/g dw) } & \multirow[t]{2}{*}{$\mathrm{Cl} \%-\mathrm{MCCPs}$} & \multicolumn{5}{|c|}{ Relative content or concentration (ng/g dw) } \\
\hline & & $\sum C_{10}$ & $\sum \mathrm{C}_{11}$ & $\sum \mathrm{C}_{12}$ & $\sum \mathrm{C}_{13}$ & $\sum \mathrm{SCCPs}$ & & $\sum \mathrm{C}_{14}$ & $\sum \mathrm{C}_{15}$ & $\sum \mathrm{C}_{16}$ & $\sum C_{17}$ & $\sum \mathrm{MCCPs}$ \\
\hline Y1 & 62.8 & 44.7 & 5.52 & 1.91 & 1.27 & 53.4 & 59.9 & 20.5 & 1.12 & 0.39 & 0.18 & 22.2 \\
\hline Y2 & 62.1 & 26.1 & 3.48 & 1.91 & 0.82 & 32.3 & 59.3 & 13.5 & 0.59 & 0.58 & 0.13 & 14.8 \\
\hline Y3 & 62.9 & 24.6 & 4.65 & 2.36 & 1.30 & 32.9 & 59.3 & 11.7 & 0.42 & 0.27 & 0.12 & 12.5 \\
\hline Y4 & 62.5 & 14.5 & 1.60 & 1.01 & 1.13 & 18.2 & 59.3 & 7.69 & 0.53 & 0.08 & 0.04 & 8.33 \\
\hline Y5 & 62.1 & 17.3 & 3.58 & 1.32 & 0.60 & 22.8 & 59.3 & 10.9 & 0.93 & 0.65 & 0.05 & 12.6 \\
\hline Y6 & 62.4 & 5.64 & 2.80 & 1.21 & 1.92 & 11.6 & 59.3 & 7.70 & 0.56 & 0.47 & 0.24 & 8.97 \\
\hline Y7 & 61.9 & 110 & 25.6 & 5.67 & 11.8 & 153 & 58.9 & 39.3 & 1.42 & 0.44 & 0.11 & 41.3 \\
\hline Y8 & 62.9 & 650 & 108 & 40.0 & 10.5 & 808 & 58.6 & 164 & 2.90 & 1.04 & 0.36 & 168 \\
\hline Y9 & 62.1 & 197 & 46.6 & 11.3 & 6.33 & 261 & 58.5 & 43.3 & 0.58 & 0.40 & 0.21 & 44.5 \\
\hline Y10 & 62.7 & 174 & 43.1 & 13.5 & 21.8 & 252 & 58.4 & 83.9 & 4.69 & 0.86 & 0.38 & 89.8 \\
\hline Y11 & 62.2 & 196 & 41.0 & 14.6 & 7.46 & 259 & 58.9 & 66.0 & 1.43 & 0.40 & 0.18 & 68.0 \\
\hline Y12 & 62.7 & 39.6 & 25.8 & 10.0 & 4.55 & 80.0 & 58.1 & 23.7 & 1.44 & 0.40 & 0.25 & 25.8 \\
\hline Y13 & 62.6 & $8.31 \times 10^{3}$ & $1.26 \times 10^{3}$ & 141 & 40.7 & $9.76 \times 10^{3}$ & 57.1 & 61.2 & 3.97 & 0.41 & 0.22 & 65.8 \\
\hline
\end{tabular}
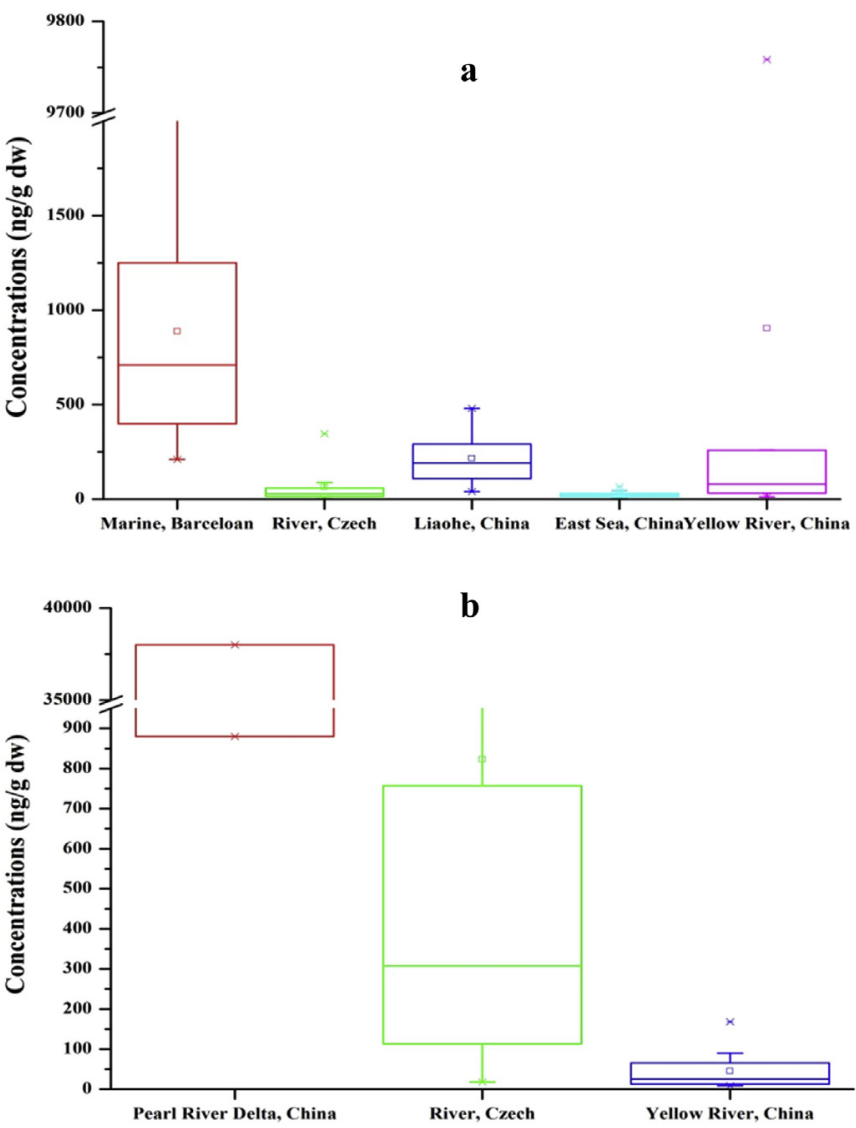

Fig. 1. Concentrations of SCCPs (a) and MCCPs (b) in sediments from the middle reaches of the Yellow River compared with those in other regions.

\subsection{Congener group profiles, sources and environmental behaviors of SCCPS and MCCPs in sediments}

The SCCP and MCCP congener group distributions in sediments from the middle reaches of the Yellow River were also analyzed. Because the sensitivity of ECNI-MS was poor for lower chlorinated $\mathrm{CPs}$, the relative abundances calculated in the study were only for CPs with 5-10 Chlorine atoms. On the whole, the $\mathrm{C}_{10}$-congeners were the most abundant, followed by $\mathrm{C}_{11}$-congeners. They accounted for $72.9-98.1 \%$ of $\Sigma$ SCCPs in total. The dominant chlorine congener groups were $\mathrm{Cl}_{6}$-and $\mathrm{Cl}_{7}$-congeners, which contributed $29.9-50.6 \%$ and $34.6-51.9 \%$, respectively. As for $\mathrm{MCCPs}, \mathrm{Cl}_{7}$-and
$\mathrm{Cl}_{8}$-congeners (65.6-87.6\%) were the major chlorine congener groups, and $\mathrm{C}_{14}$-congeners $(85.8-97.4 \%)$ were the main carbon chain congeners. The SCCP homolog patterns were similar to those found in sediments from the Liaohe River Basin and the East China Sea (Gao et al., 2012; Zeng et al., 2012a), which were dominated by shorter carbon chain congeners. $C_{10}$-congeners and $C_{11}$-congeners can together contribute more than $70 \%$ of the total SCCP concentrations. However, the profiles were different from those found in sediments from the highly industrialized regions (Chen et al., 2011), in which $\mathrm{C}_{10^{-}}, \mathrm{C}_{11^{-}}, \mathrm{C}_{12^{-}}$and $\mathrm{C}_{13^{-}}$-congeners contributed similar proportion.

Meanwhile, it's worth noting that the specific proportions of each congener group were slightly different among all sampling sites. In order to expound the congener group profiles of SCCPs in sediments, hierarchical cluster analysis (HCA) was carried out. All samples were clustered according to the percentages of 24 SCCP congener groups $\left(\mathrm{C}_{10}-\mathrm{C}_{13}\right.$ with 5-10 chlorine atoms) in $\sum \mathrm{SCCPs}$ and $24 \mathrm{MCCP}$ congener groups $\left(\mathrm{C}_{14}-\mathrm{C}_{17}\right.$ with $5-10$ chlorine atoms) in $\sum$ MCCPs, respectively (Fig. S2). The average congener group profiles of SCCPs and MCCPs in sediments classified by HCA can be obtained (Fig. S3). The most abundant SCCP congener groups in cluster $1(\mathrm{n}=11)$ were $\mathrm{C}_{10} \mathrm{Cl}_{6-7}$. While the predominant SCCP homolog groups in cluster $2(\mathrm{n}=2)$ were $\mathrm{C}_{10} \mathrm{Cl}_{6-7}$ and $\mathrm{C}_{11} \mathrm{Cl}_{6-7}$. The most abundant MCCP homolog groups in cluster $1(\mathrm{n}=9)$ were $\mathrm{C}_{14} \mathrm{Cl}_{7-8}$. By contrast, only $\mathrm{C}_{14} \mathrm{Cl}_{8}$ dominated in the MCCP compositions in cluster $2(\mathrm{n}=4)$.

For investigating the sources of SCCPs in these sediments, principal component analysis (PCA) was performed on the correlation matrix of the relative abundances of SCCP homolog groups in the sediment samples and suspected sources (Lu et al., 2015; Zeng et al., 2011b). As shown in Fig. 3, three principal components with eigenvalues $>1$ were extracted to account for $85.6 \%$ of the total variance. And the result indicated that SCCPs in sediments from the middle reaches of the Yellow River probably originated from the production and use of commercial mixtures CP-42 and CP-52.

Interestingly, the congener group profiles in the sediments distinguished from those in commercial CP mixtures to some extent, as shown in Fig. 4. This was probably relevant to the differences in the physicochemical properties between congeners, which directly affected their environmental behaviors. It has been found that vapor pressures of CPs are inclined to decrease with increasing carbon atoms (Drouillard et al., 1998). The log octanolwater partition coefficients ( $\left.\log \mathrm{K}_{\mathrm{OW}}\right)$ of CPs increase almost linearly with increasing carbon chain length (Hilger et al., 2011). Therefore, shorter carbon-chain congeners, owing to higher volatility and water solubility, tend to undergo long-range transport via the atmosphere and/or river. Their potential for long range 


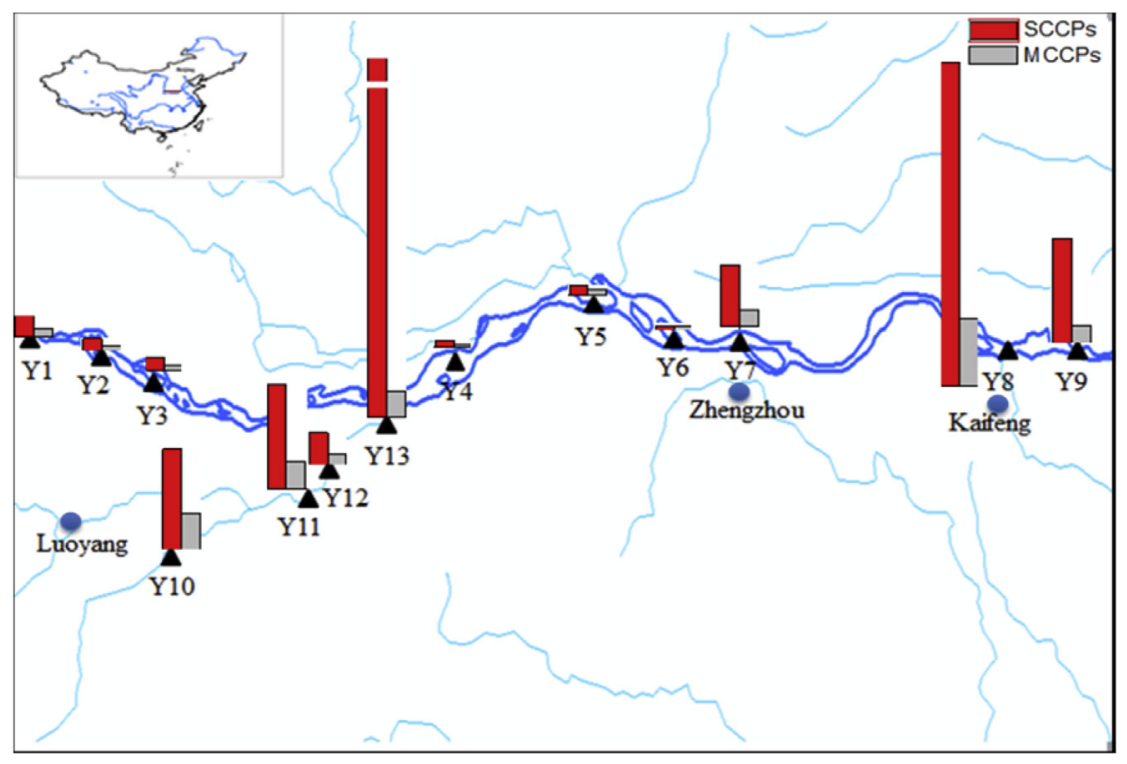

Fig. 2. Spatial distributions of SCCPs and MCCPs in the sediment samples.

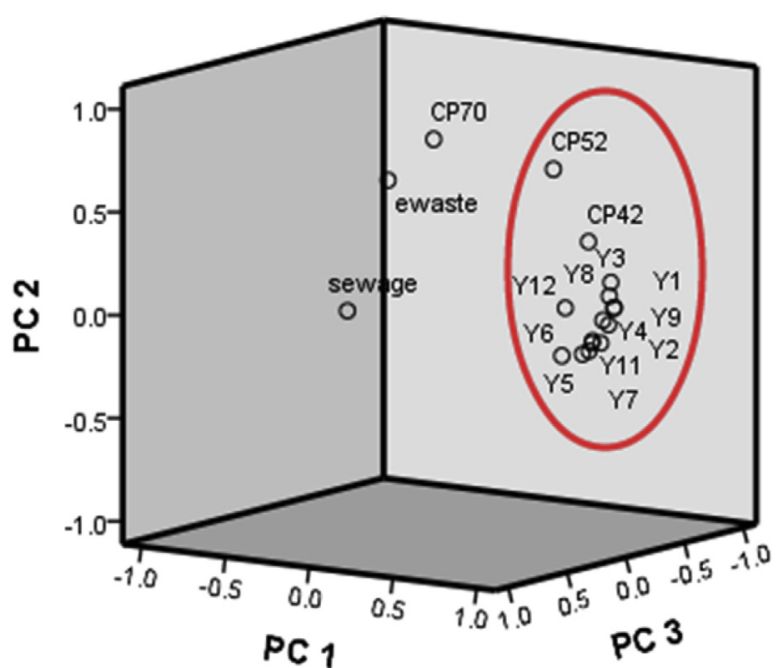

Fig. 3. Score plot of principal component analysis from relative abundances of SCCP congeners in sediment samples and suspected sources ("ewaste" means e-waste dismantling residue, and "sewage" means sewage treatment plant effluent).

transport could be supported by the SCCPs found in Arctic (Vorkamp and Riget, 2014) and Antarctic (Ma et al., 2014c). While longer carbon-chain congeners with high hydrophobicity are easily adsorbed into adjacent sediments. In fact, the relative abundances of shorter chain congener groups $\left(\mathrm{C}_{10}-\mathrm{CPs}\right)$ in sediments were higher than those in commercial mixtures CP-42 and CP-52, and the relative abundances of longer chain congener groups $\left(\mathrm{C}_{11^{-}}\right.$and $\mathrm{C}_{12}$-CPs) in sediments (except for samples Y6 and Y12) were lower compared with those in CP-42 and CP-52. So it can be inferred that long-range transport via the atmosphere and/or river as well as deposition may be major pathways for SCCPs into sediments. This would also explain why the abundance of short chain congener groups $\left(\mathrm{C}_{10}-\mathrm{CPs}\right)$ in sediments collected in the rural areas (site Y1) was increased compared with sediments near the cities (site Y5). Moreover, SCCP homolog patterns in the sediments were similar to those found in the atmosphere (Wang et al., 2012), which can further illustrate that long-range atmospheric transport may be

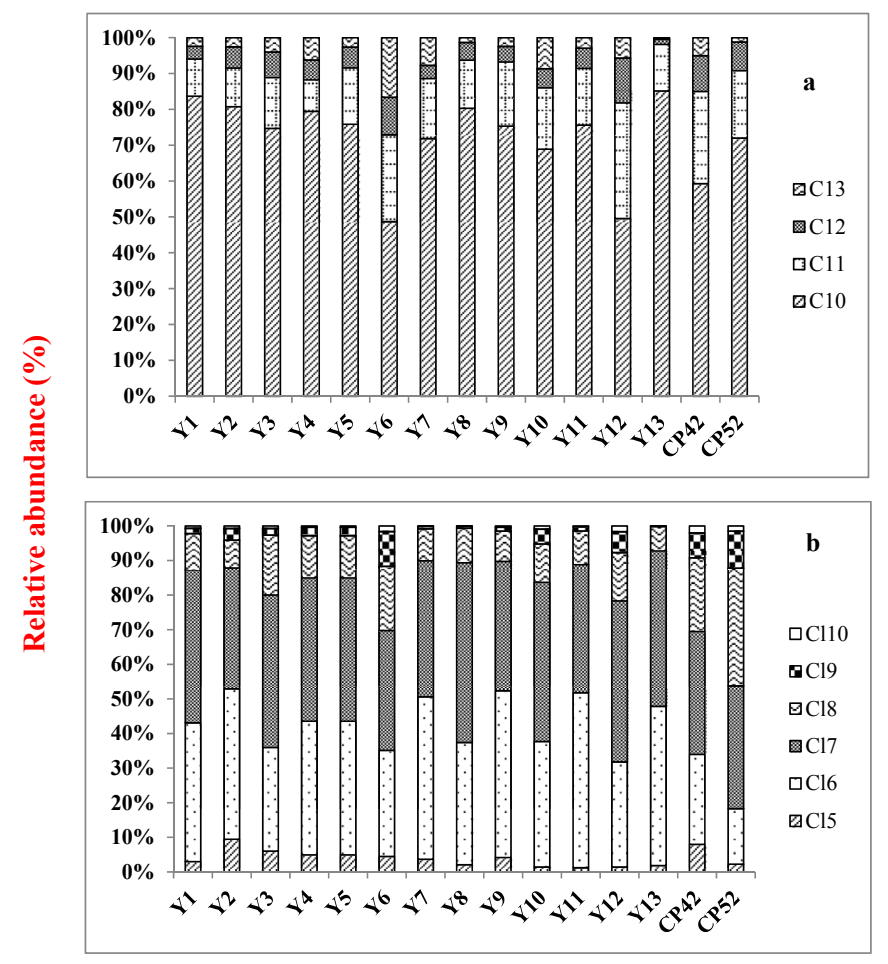

Fig. 4. Differences in the congener group profiles of SCCPs between the sediments and commercial mixtures $\mathrm{CP}-42$ and $\mathrm{CP}-52$.

one pathway for SCCPs moving from sources to contaminated regions.

As for the abnormal phenomena observed in sites Y6 and Y12, the environmental fates of SCCP congeners may be simultaneously influenced by other factors. It was found that the TOC contents in samples Y6 (1.87\%) and Y12 (1.73\%) were higher than those in other samples. Longer carbon chain congeners may therefore be more easily adsorbed into sediments at sampling sites Y6 and Y12. Meanwhile, shorter carbon chain congeners were prone to undergo long-range atmospheric and/or waterborne transport. Under the 
joint action of migration and adsorption, a larger proportion of $\mathrm{C}_{11}$ CPs rather than $\mathrm{C}_{10}$-CPs was observed in sediments compared with commercial CP mixtures. In addition, the degradation of SCCPs propelled by microbes in sediments may also play an important role (Persistent Organic Pollutants Review Committee, 2012; UK Environment Agency, 2007). It has been found that SCCPs become less susceptible to aerobic biodegradation as the carbon chain length increases (Fisk et al., 1998; Omori et al., 1987). That is to say, congeners with short carbon chains are more easily degraded in surface sediments, especially under the condition of many microorganisms, causing the further decrease of $\mathrm{C}_{10}$-CPs.

Similarly, the relative abundances of SCCP congeners based on the number of chlorine atoms in sediment samples were also compared with those in the commercial mixtures, as shown in Fig. 4(b). It should be noted that ECNI-MS only detected CPs with more than 5 Chlorine atomes. Results indicated that the proportion of SCCPs with six to seven chlorine atoms increased, while the proportion of SCCPs with eight to ten chlorine atoms decreased in sediments. Differences in the transfer abilities of SCCP congeners with different chlorine contents may result in the varying congener group profiles between environmental samples and commercial mixtures. What's more, the dechlorination of higher chlorinated congeners to the lower chlorinated congeners may be another reason.

Furthermore, PCA was applied to explore the correlation between SCCPs and MCCPs (Fig. S4). The result indicated that SCCPs and MCCPs in sediments from the middle reaches of the Yellow River may come from different sources. Data on MCCP levels in commercial $\mathrm{CP}$ mixtures and emissions during industrial processes are not sufficient at present. So the sources of MCCPs in the sediments were unable to identify.

\subsection{Relationship between SCCPs and MCCPS}

Except for the fractionation within SCCPs, fractionation can also occur between MCCPs and SCCPs during a series of environmental processes. In consideration of physicochemical properties of CPs, MCCPs are prone to adsorb onto particles and harder to undergo long-range transport compared to SCCPs. This would result in higher MCCP/SCCP ratios in sediment samples near cities where more human activities take place, and lower ratios in the countryside. For example, the MCCP/SCCP ratios in samples Y6, Y8, Y10 (close to cities Zhengzhou, Kaifeng, and Luoyang, respectively) were respectively higher than the ratios in samples Y3, Y9 and Y11 (far away from cities Zhengzhou, Kaifeng, and Luoyang, respectively) (Fig. S5). But the opposites were also observed in a few cases, such as the ratios in sample Y3 than Y2, and in sample Y11 than Y12, where sites Y3 and Y11 were closer to the city. This may be caused by increased TOC contents in those sediments (sites Y2 and Y12), leading more MCCPs to be accumulated.

Furthermore, the relationship between SCCP concentrations $\left(\log _{10}\right.$ (SCCPs)) and MCCP/SCCP ratios was analyzed, as shown in Fig. 5. Because SCCPs have higher volatility and water solubility than MCCPs, they are more likely to undergo long-range transport via the atmosphere and/or river. Referring to the previous study (Chen et al., 2011), a significant negative correlation between $\log _{10}$ (SCCPs) and MCCP/SCCP ratios was found in the upper reaches of Dayan River due to no direct industrial emission. However, a significant positive correlation was found in the section with e-waste activities. Thus, the negative correlation obtained in this study can be used to infer that there is no direct emission source of CPs in the sampling regions, and long-range transport may be the major pathway for CPs into the sediments.

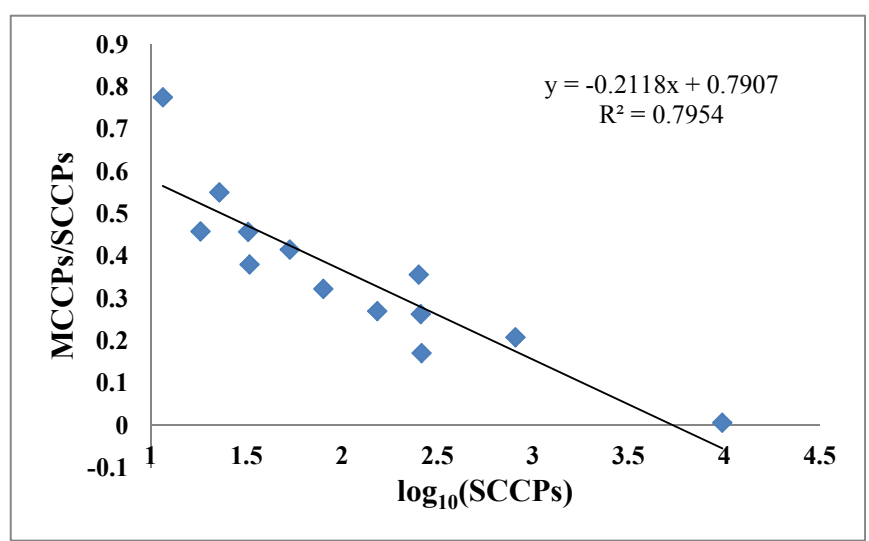

Fig. 5. The relationship between MCCP/SCCP ratios and $\log _{10}$ (SCCPs) in sediments.

\subsection{Risk assessment}

Only a few aquatic toxicity data of CPs are available, especially for sediment-dwelling organisms, so it is difficult to comprehensively assess the ecological risks posed by CPs at present. However, an elementary risk assessment can be conducted using CP concentrations in our samples and toxicology thresholds that have been derived. An equilibrium partitioning approach identified for a pelagic freshwater invertebrate $(8.9 \mu \mathrm{g} / \mathrm{L})$ was used to estimate the toxicity of SCCPs to benthic organisms, and the estimated lowest observed effect concentration (LOEC) was $35.5 \mathrm{mg} / \mathrm{kg}$ dw (UNEP, 2015). The SCCP concentrations obtained from the present study $\left(11.6-9.76 \times 10^{3} \mathrm{ng} / \mathrm{g} \mathrm{dw}\right)$ were far lower than the value, indicating that SCCPs in sediments from the middle reaches of the Yellow River currently pose no significant ecological risk. Since the exposure parameters of humans to CPs in sediments are inadequate, it is unable to assess the human health risks at present. However, in view of the increasing mass loads of SCCPs over time and possible interaction effects with other POPs, attention should still be paid to the contamination levels as well as ecological and human health risks posed by CPs in sediments.

\section{Conclusions}

SCCPs and MCCPs in sediments from the middle reaches of the Yellow River were investigated using GC $\times$ GC - TOFMS for the first time. The SCCP and MCCP concentrations in the sediments were in lower or comparable level compared with the concentrations found in other parts of the world. Spatial distributions showed that the contamination levels of CPs were related to human activities. The most abundant congener groups were $\mathrm{C}_{10} \mathrm{Cl}_{6-7}$ and $\mathrm{C}_{14} \mathrm{Cl}_{7-8}$. MCCPs in the sediments may have different sources with SCCPs, and SCCPs may mainly come from the production and use of CP-42 and CP-52. Besides, increased abundances of short chain and low chlorinated congeners in sediment samples compared with commercial mixtures were observed, implying that long-range transport via the atmosphere and/or river, as well as deposition may be major pathways for SCCPs into sediments. Meanwhile, the microbiological degradation and dechlorination of CPs also occurred. The properties of CP congeners and environmental conditions of sediments both play important roles in CP congener patterns in the sampling sites. The relationship between SCCPs and MCCPs can give implication that there is no significant emission source next to the sampling locations. A preliminary risk assessment indicated that CPs in sediments from the middle reaches of the Yellow River posed no significant ecological risk. Further work is needed to 
identify the congeners with less than ten carbon atoms, which may be more toxic than congeners with longer carbon chains. The toxicities of CPs to sediment-dwelling organisms and the pathways through which humans are exposed to CPs need to be studied in more depth, so that the ecological and human health risks posed by CPs can be evaluated more comprehensively than is currently possible.

\section{Acknowledgements}

This research was funded by the National Natural Science Foundation of China (Nos. 21377140, 213111064 and 21321004) and the Chinese Academy of Sciences "Strategic Leading Science and Technology Projects" (XDB14020000 and XDB14020102).

\section{Appendix A. Supplementary data}

Supplementary data related to this article can be found at http:// dx.doi.org/10.1016/j.envpol.2016.05.057.

\section{References}

Bayen, S., Obbard, J.P., Thomas, G.O., 2006. Chlorinated paraffins: a review of analysis and environmental occurrence. Environ. Int. 32, 915-929.

Castells, P., Parera, J., Santos, F.J., Galceran, M.T., 2008. Occurrence of polychlorinated naphthalenes, polychlorinated biphenyls and short-chain chlorinated paraffins in marine sediments from Barcelona (Spain). Chemosphere 70, 1552-1562.

Chen, M.Y., Luo, X.J., Zhang, X.L., He, M.J., Chen, S.J., Mai, B.X., 2011. Chlorinated paraffins in sediments from the Pearl River Delta, South China: spatial and temporal distributions and implication for processes. Environ. Sci. Technol. 45 9936-9943.

Coelhan, M., 2010. Levels of chlorinated paraffins in water. Clean-Soil Air Water 38 $452-456$.

De Boer, J., El-Sayed Ali, T., Fiedler, H., Legler, J., Muir, D.C., Nikiforov, V.A., Tomy, G.T., Tsunemi, K., 2010. Chlorinated paraffins. In: De Boer, J. (Ed.), The Handbook of Environmental Chemistry. Chlorinated Paraffins, vol. 10. Springer-Verlag, Berlin/ Heidelberg.

Drouillard, K.G., Tomy, G.T., Muir, D.C.G., Friesen, K.J., 1998. Volatility of chlorinated n-alkanes (C-10-C-12): vapor pressures and Henry's law constants. Environ. Toxicol. Chem. 17, 1252-1260.

EU, 2011. European Union Risk Assessment Report, Alkanes, C14-17, Chloro, Part I - Human Health. European Commission Joint Research Centre.

Feo, M.L., Eljarrat, E., Barceló, D., Barceló, D., 2009. Occurrence, fate and analysis of polychlorinated n-alkanes in the environment. Trac-Trend. Anal. Chem. 28 778-791.

Fisk, A.T., Tomy, G.T., Cymbalisty, C.D., Muir, D.C.G., 2000. Dietary accumulation and quantitative structure-activity relationships for depuration and biotransformation of short (C-10), medium (C-14), and long (C-18) carbon-chain polychlorinated alkanes by juvenile rainbow trout (Oncorhynchus mykiss). Environ. Toxicol. Chem. 19, 1508-1516.

Fisk, A.T., Wiens, S.C., Webster, G.R.B., Bergman, W., Muir, D.C.G., 1998. Accumulation and depuration of sediment-sorbed C-12- and C-16-polychlorinated alkanes by oligochaetes (Lumbriculus variegatus). Environ. Toxicol. Chem. 17, 2019-2026.

Gao, Y., Zhang, H.J., Chen, J.P., Zhang, Q., Tian, Y.Z., Qi, P.P., Yu, Z.K., 2011. Optimized cleanup method for the determination of short chain polychlorinated n-alkanes in sediments by high resolution gas chromatography/electron capture negative ion-low resolution mass spectrometry. Anal. Chim. Acta 703, 187-193.

Gao, Y., Zhang, H.J., Su, F., Tian, Y.Z., Chen, J.P., 2012. Environmental occurrence and distribution of short chain chlorinated paraffins in sediments and soils from the Liaohe River Basin, P. R. China. Environ. Sci. Technol. 46, 3771-3778.

Hilger, B., Fromme, H., Volkel, W., Coelhan, M., 2011. Effects of chain length, chlorination degree, and structure on the octanol-water partition coefficients of polychlorinated n-alkanes. Environ. Sci. Technol. 45, 2842-2849.

Houde, M. Muir, D.C.G. Tomy, G.T., Whittle, D.M. Teixeira, C., Moore, S., 2008 Bioaccumulation and trophic magnification of short- and medium-chain chlorinated paraffins in food webs from Lake Ontario and Lake Michigan. Environ. Sci. Technol. 42, 3893-3899.

Hussy, I., Webster, L., Russell, M., Moffat, C., 2012. Determination of chlorinated paraffins in sediments from the Firth of Clyde by gas chromatography with electron capture negative ionisation mass spectrometry and carbon skeleton analysis by gas chromatography with flame ionisation detection. Chemosphere $88,292-299$

Iozza, S., Muller, C.E., Schmid, P., Bogdal, C., Oehme, M., 2008. Historical profiles of chlorinated paraffins and polychlorinated biphenyls in a dated sediment core from Lake Thun (Switzerland). Environ. Sci. Technol. 42, 1045-1050.

Lu, F.H., Chen, M.Y., Chen, Y.W., Liu, F.J., Luo, X.J., Mai, B.X., 2015. Distribution of chlorinated paraffins and polychlorinated biphenyls in e-waste, residues and sediment from e-waste areas of Qingyuan. Environ. Chem. 34, 1297-1303 (in Chinese).

Ma, X.D., Chen, C., Zhang, H.J., Gao, Y., Wang, Z., Yao, Z.W., Chen, J.P., Chen, J.W., 2014a. Congener-specific distribution and bioaccumulation of short-chain chlorinated paraffins in sediments and bivalves of the Bohai Sea, China. Mar. Pollut. Bull. 79, 299-304.

Ma, X.D., Zhang, H.J., Wang, Z., Yao, Z.W., Chen, J.W., Chen, J.P., 2014b. Bioaccumulation and trophic transfer of short chain chlorinated paraffins in a marine food web from Liaodong Bay, North China. Environ. Sci. Technol. 48, 5964-5971.

Ma, X.D., Zhang, H.J., Zhou, H.Q., Na, G.S., Wang, Z., Chen, C., Chen, J.W., Chen, J.P., 2014c. Occurrence and gas/particle partitioning of short- and medium-chain chlorinated paraffins in the atmosphere of Fildes Peninsula of Antarctica. Atmos. Environ. 90, 10-15.

Omori, T., Kimura, T., Kodama, T., 1987. Bacterial cometabolic degradation of chlorinated paraffins. Appl. Microbiol. Biot. 25, 553-557.

Persistent Organic Pollutants Review Committee, 2012. Short-chained Chlorinated Paraffins Revised Draft Risk Profile. Stockholm Convention on Persistent Organic Pollutants.

Pribylova, P., Klanova, J., Holoubek, I., 2006. Screening of short- and medium-chain chlorinated paraffins in selected riverine sediments and sludge from the Czech Republic. Environ. Pollut. 144, 248-254.

Reth, M., Ciric, A., Christensen, G.N., Heimstad, E.S., Oehme, M., 2006. Short- and medium-chain chlorinated paraffins in biota from the European Arctic - differences in homologue group patterns. Sci. Total. Environ. 367, 252-260.

Reth, M., Zencak, Z., Oehme, M., 2005. New quantification procedure for the analysis of chlorinated paraffins using electron capture negative ionization mass spectrometry. J. Chromatogr. A 1081, 225-231.

Thomas, G.O., Farrar, D., Braekevelt, E., Stern, G., Kalantzi, O.I., Martin, F.L., Jones, K.C., 2006. Short and medium chain length chlorinated paraffins in UK human milk fat. Environ. Int. 32, 34-40.

Tomy, G.T., Stern, G.A., Lockhart, W.L., Muir, D.C.G., 1999. Occurrence of C-10-C-13 polychlorinated n-alkanes in Canadian midlatitude and arctic lake sediments. Environ. Sci. Technol. 33, 2858-2863.

UK Environment Agency, 2007. Updated risk assessment of alkanes, C10-13 chloro. CAS Number 85535-84-8. EINECS Number: 287-476-5. In: Agency, U.K.E. (Ed.), Combined Draft of April 2007, Oxfordshire, UK.

UNEP, 2015. Risk Profile on Short-chained Chlorinated Paraffins. UNEP/POPS/ POPRC.11/10/Add.2. http://chm.pops.int/Convention/POPsReviewCommittee/ Chemicals/tabid/243/Default.aspx.

Vorkamp, K., Riget, F.F., 2014. A review of new and current-use contaminants in the Arctic environment: evidence of long-range transport and indications of bioaccumulation. Chemosphere 111, 379-395.

Wang, T., Han, S.L., Yuan, B., Zeng, L.X., Li, Y.M., Wang, Y.W., Jiang, G.B., 2012. Summerwinter concentrations and gas-particle partitioning of short chain chlorinated paraffins in the atmosphere of an urban setting. Environ. Pollut. 171, 38-45.

Wang, X.T., Wang, X.K., Zhang, Y., Chen, L., Sun, Y.F., Li, M., Wu, M.H., 2014. Shortand medium-chain chlorinated paraffins in urban soils of Shanghai: spatial distribution, homologue group patterns and ecological risk assessment. Sci. Total. Environ. 490, 144-152.

Wang, Y., Li, J., Cheng, Z.N., Li, Q.L., Pan, X.H., Zhang, R.J., Liu, D., Luo, C.L., Liu, X., Katsoyiannis, A., Zhang, G., 2013. Short- and medium-chain chlorinated paraffins in air and soil of subtropical terrestrial environment in the pearl river delta, South China: distribution, composition, atmospheric deposition fluxes, and environmental fate. Environ. Sci. Technol. 47, 2679-2687.

Warnasuriya, G.D., Elcombe, B.M., Foster, J.R., Elcombe, C.R., 2010. A mechanism for the induction of renal tumours in male Fischer 344 rats by short-chain chlorinated paraffins. Arch. Toxicol. 84, 233-243.

Wyatt, I., Coutts, C.T., Elcombe, C.R., 1993. The effect of chlorinated paraffins on hepatic-enzymes and thyroid-hormones. Toxicology 77, 81-90.

Xia, D., Gao, L.R., Zheng, M.H., Tian, Q.C., Huang, H.T., 2016. A novel method for profiling and quantifying short- and medium-chain chlorinated paraffins in environmental samples using GC $\times$ GC-ECNI-HRTOF-MS. Environ. Sci. Technol. http://dx.doi.org/10.1021/acs.est.6b01404.

Zeng, L.X., Chen, R., Zhao, Z.S., Wang, T., Gao, Y., Li, A., Wang, Y.W., Jiang, G.B., Sun, L.G., 2013. Spatial distributions and deposition chronology of short chain chlorinated paraffins in marine sediments across the Chinese Bohai and Yellow Seas. Environ. Sci. Technol. 47, 11449-11456.

Zeng, L.X., Wang, T., Han, W.Y., Yuan, B., Liu, Q., Wang, Y.W., Jiang, G.B., 2011a. Spatial and vertical distribution of short chain chlorinated paraffins in soils from wastewater irrigated farmlands. Environ. Sci. Technol. 45, 2100-2106.

Zeng, L.X., Wang, T., Wang, P., Liu, Q., Han, S.L., Yuan, B., Zhu, N., Wang, Y.W., Jiang, G.B., 2011b. Distribution and trophic transfer of short-chain chlorinated paraffins in an aquatic ecosystem receiving effluents from a sewage treatment plant. Environ. Sci. Technol. 45, 5529-5535.

Zeng, L.X., Zhao, Z.S., Li, H.J., Wang, T., Liu, Q., Xiao, K., Du, Y.G., Wang, Y.W., Jiang, G.B., 2012a. Distribution of short chain chlorinated paraffins in marine sediments of the East China Sea: influencing factors, transport and implications. Environ. Sci. Technol. 46, 9898-9906.

Zeng, L.X., Lam, J.C.W., Wang, Y.W., Jiang, G.B., Lam, P.K.S., 2015. Temporal trends and pattern changes of short- and medium-chain chlorinated paraffins in marine mammals from the South China Sea over the past decade. Environ. Sci. Technol. 49, 11348-11355.

Zeng, L.X., Wang, T., Ruan, T., Liu, O. Wang, Y.W., Jiang, G.B., 2012b. Levels and distribution patterns of short chain chlorinated paraffins in sewage sludge of wastewater treatment plants in China. Environ. Pollut. 160, 88-94. 